\title{
Impacts of Agricultural Practices on Insecticide Resistance in the Malaria Vector Anopheles arabiensis in Khartoum State, Sudan
}

\author{
Sara A. Abuelmaali ${ }^{* \odot}$, Arwa H. Elaagip ${ }^{2 \odot}$, Mohammed A. Basheer ${ }^{3}$, Ehab A. Frah ${ }^{3}$, Fayez T. A. Ahmed ${ }^{1}$, \\ Hassabelrasoul F. A. Elhaj ${ }^{1}$, Osama M. E. Seidahmed ${ }^{1}$, David Weetman ${ }^{4}$, Muzamil Mahdi Abdel Hamid ${ }^{5 \odot}$ \\ 1 Department of Medical Entomology, National Public Health Laboratory, Federal Ministry of Health, Khartoum, Sudan, 2 Department of Parasitology and \\ Medical Entomology, Faculty of Medical Laboratory Sciences, University of Khartoum, Khartoum, Sudan, 3 Tropical Medicine Research Institute, National \\ Center for Research, Khartoum, Sudan, 4 Department of Vector Biology, Liverpool School of Tropical Medicine, Liverpool, United Kingdom, $\mathbf{5}$ Department of \\ Molecular Biology, Institute of Endemic Diseases, University of Khartoum, Khartoum, Sudan
}

\begin{abstract}
Background: Agricultural pesticides may play a profound role in selection of resistance in field populations of mosquito vectors. The objective of this study is to investigate possible links between agricultural pesticide use and development of resistance to insecticides by the major malaria vector Anopheles arabiensis in northern Sudan.

Methodology/Principal Findings: Entomological surveys were conducted during two agricultural seasons in six urban and peri-urban sites in Khartoum state. Agro-sociological data were collected from 240 farmers subjected to semi-structured questionnaires based on knowledge attitude and practice (KAP) surveys. Susceptibility status of An. arabiensis $(n=6000)$ was assessed in all sites and during each season using WHO bioassay tests to DDT, deltamethrin, permethrin, Malathion and bendiocarb. KAP analysis revealed that pesticide application was common practice among both urban and peri-urban farmers, with organophosphates and carbamates most commonly used. Selection for resistance is likely to be greater in peri-urban sites where farmers apply pesticide more frequently and are less likely to dispose of surpluses correctly. Though variable among insecticides and seasons, broad-spectrum mortality was slightly, but significantly higher in urban than peri-urban sites and most marked for bendiocarb, to which susceptibility was lowest. Anopheles arabiensis from all sites showed evidence of resistance or suspected resistance, especially pyrethroids. However, low-moderate frequencies of the L1014F kdr allele in all sites, which was very strongly associated with DDT, permethrin and deltamethrin survivorship (OR=6.14-14.67) suggests that resistance could increase rapidly.

Conclusions: Ubiquitous multiple-resistance coupled with presence of a clear mechanism for DDT and pyrethroids $(k d r \mathrm{~L} 1014 \mathrm{~F})$ in populations of An. arabiensis from Khartoum-Sudan suggests careful insecticide management is essential to prolong efficacy. Our findings are consistent with agricultural insecticide use as a source of selection for resistance and argue for coordination between the integrated vector control program and the Ministry of Agriculture to permit successful implementation of rational resistance management strategies.
\end{abstract}

Citation: Abuelmaali SA, Elaagip AH, Basheer MA, Frah EA, Ahmed FTA, et al. (2013) Impacts of Agricultural Practices on Insecticide Resistance in the Malaria Vector Anopheles arabiensis in Khartoum State, Sudan. PLoS ONE 8(11): e80549. doi:10.1371/journal.pone.0080549

Editor: Basil Brooke, National Institute for Communicable Diseases/NHLS, South Africa

Received July 4, 2013; Accepted October 4, 2013; Published November 18, 2013

Copyright: @ 2013 Abuelmaali et al. This is an open-access article distributed under the terms of the Creative Commons Attribution License, which permits unrestricted use, distribution, and reproduction in any medium, provided the original author and source are credited.

Funding: This work received financial support from WHO TDR/EMRO small grants (ID No. SGS 10/46). The funders had no role in study design, data collection and analyses, decision to publish, or preparation of the manuscript.

Competing interests: The authors have declared that no competing interests exist.

*E-mail: profsara83@gmail.com

(.) These authors contributed equally to this work.

\section{Introduction}

Malaria constitutes a major public health problem in Khartoum state, leading to about 300,000 cases and five hundred deaths each year [1,2]. Both urban and peri-urban agricultural areas have been expanded in response to high demand for accommodation and food. However, the relative rate of expansion varies between the state's districts, due to differences in landscape and the livelihoods of the local community [3]. The WHO recommends large-scale distribution of insecticide-treated nets (ITNs) to control malaria transmission. Recently, concerted international efforts have been devoted to distribute ITNs and also to increase Indoor Residual Spraying (IRS), which has contributed to a major 
reduction in disease burden in sub-Saharan Africa [4,5]. Likewise ITNs and IRS, are the main vector control strategies for malaria in Sudan [6].

In contrast to wider malaria control practice, the main vector control intervention in Khartoum state is larval control using the organophosphate insecticide Temephos, particularly in urban areas $[1,2,7,8]$. On the other hand environmental management through weekly drying of irrigation canals (intermittent irrigation) is more common in the peri-urban areas of the state $[2,3]$. In addition space spraying of insecticides and IRS is occasionally used when mosquito densities increase or if a malaria outbreak is suspected. Despite ongoing scale-up in other parts of Sudan coverage with ITNs is still very low in Khartoum $[2,3,9]$.

Resistance of mosquito vectors to insecticide remains one of the major challenges facing malaria control programs [5]. Resistance to pyrethroids and DDT in An. gambiae s.s. and An. arabiensis, two important African malaria vectors, is particularly widespread [10,11,12]. Pyrethroids and DDT both target a voltage-gated sodium channel, and substitutions of the leucine residue at codon 1014 (L1014F and L1014S) can lead to target site insensitivity known as knock down resistance (kdr). In An. arabiensis populations the L1014F allele has been found widely across many eastern and western African countries $[6,13,14,15,16]$.

Owing to pyrethroid and DDT resistance and crossresistance,, carbamate and organophosphate insecticides, which have a different mode of action, represent important alternatives for IRS.

And are increasingly used in sub-Saharan Africa as a replacement to pyrethroids [17]. Organophosphate resistance has been documented in $A n$. arabiensis from Sudan and neighboring Ethiopia $[18,19,20]$, but available studies suggest predominant susceptibility to carbamates $[18,20]$. Nevertheless, more information on the susceptibility levels of populations of An. arabiensis to carbamates and organophosphates is required. In addition the strength of association of $k d r$ with DDT and pyrethroid cross-resistance phenotypes requires further exploration[21], because metabolic resistance mechanisms may also be associated with pyrethroids resistance in An. arabiensis [22].

Elucidating the susceptibility status of local populations of An. arabiensis to insecticides is therefore essential, particularly in urban settings that may be influenced by small-scale landscape and livelihood variations [3]. The aim of this study was to investigate the effect of habitat type (urban and periurban) and agricultural season (summer and winter) on insecticide resistance in An. arabiensis in Khartoum state, Sudan to investigate the hypothesis that agricultural pesticide use will favour resistant phenotypes.

\section{Materials and Methods}

\section{Ethics statement}

Ethical approval for the study was granted by the Ethical Review Committee of the Ministry of Health, Sudan (2010). The objectives and procedures of the study were explained to the local health authorities and to the Khartoum malaria control program. Agreement for the use of data from any farmer recruited to fill the questionnaire was obtained. Field studies did not involve endangered or protected species.

\section{Study sites}

Khartoum state lies in a poor savannah region, characterized by a short rainy season (July to September), winter season (October to March) and summer season (April to July). The total area of the state is $28000 \mathrm{~km}^{2}$; it is divided by the Blue Nile, White Nile and River Nile into three greater administrative areas: Khartoum North, Khartoum and Omdurman. These areas differ in their topography, agriculture and socioeconomic activities. Agricultural activities (mainly along River Nile banks) are the main source of mosquito breeding sites in the River Nile bank areas. Entomological cross-sectional surveys were carried out in Khartoum in six sites categorized as urban and peri-urban where agricultural schemes were found. The urban sites are: Soba West $\left(32^{\circ} 38^{\prime} 14.74 " \mathrm{E}, 15^{\circ} 31^{\prime} 3.49 " \mathrm{~N}\right)$, Alremaila $\left(32^{\circ} 30^{\prime} 16.03^{\prime \prime E}, 15^{\circ} 34^{\prime} 24.44^{\prime \prime N}\right)$, Tuti island $\left(32^{\circ} 30^{\prime} 20.69^{\prime \prime E}\right.$, $\left.15^{\circ} 37^{\prime} 13.69 " \mathrm{~N}\right)$, and the peri-urban: Althamaniat $\left(32^{\circ} 34^{\prime} 52.18^{\prime \prime} \mathrm{E}, 1^{\circ} 57^{\prime} 44.50^{\prime \prime N}\right)$, Algamoyia $\left(32^{\circ} 26^{\prime} 56.48^{\prime \prime} \mathrm{E}\right.$, $\left.15^{\circ} 23^{\prime} 14.08^{\prime \prime} \mathrm{N}\right), \quad$ Alseliat $\left(32^{\circ} 36^{\prime} 47.22 " \mathrm{E}, \quad 15^{\circ} 46^{\prime} 41.67^{\prime \prime} \mathrm{N}\right)$ (Figure 1). The entomological surveys were conducted during two agricultural seasons: winter (November 2010- March 2011) and summer (April - May 2011). Malaria transmission in the area is unstable and highly seasonal [1]. The primary economic activity of local people in both study sites is farming.

\section{Mosquito collections and morphological identification}

Larvae and pupae of Anopheles mosquitoes were collected by dipping from a range of different breeding sites to represent the diversity of the mosquito populations in each study area. Samples were transported to the reference laboratory of mosquito rearing in the Department of Medical Entomology, Federal Ministry of Health, Sudan then reared to adults under standard insectary conditions $\left(25 \pm 2^{\circ} \mathrm{C}, \quad 70-80 \%\right.$ relative humidity). Adult Anopheles mosquitoes were identified to species according to the morphological key [23].

\section{Insecticide susceptibility tests}

Susceptibility tests were conducted according to standard WHO bioassay protocol. Insecticide impregnated papers with discriminating concentrations of: DDT $(4 \%)$, permethrin $(0.75 \%)$, deltamethrin $(0.05 \%)$, malathion $(5 \%)$ and bendiocarb $(0.1 \%)$ were used. A laboratory susceptible strain of $A n$. arabiensis -Dongola colony-was used as a reference colony to test the efficacy of the impregnated papers. For each insecticide five batches of twenty (2-3 day-old sugar-fed) females were exposed to impregnated paper for one hour. Controls included batches of mosquitoes from each site exposed to untreated papers. The number "knocked-down" was recorded at different time intervals $(10,15,20,30,40,50$, and 60 minutes) and after 60 min exposure mosquitoes were transferred into holding tubes and provided with cotton wools soaked with a $10 \%$ sucrose solution. Mortalities were recorded 24 hours post-exposure [24]. Dead and surviving mosquitoes from each bioassay were kept separately in eppendorf tubes over silica gel for subsequent molecular analysis. 


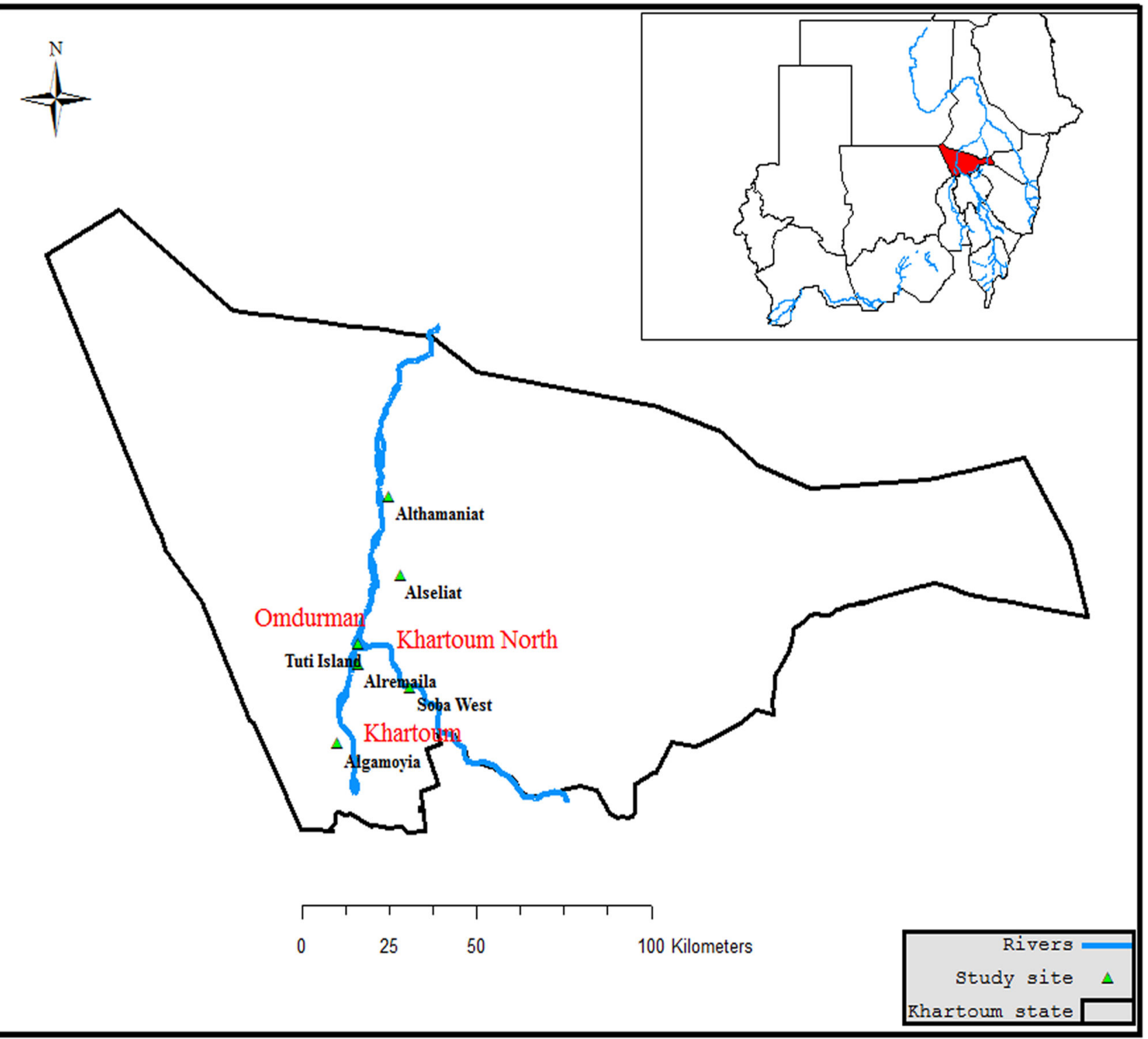

Figure 1. Map showing the study sites in Khartoum state, Sudan including urban sites (Soba West, Alremaila, Tuti island) and peri-urban sites (Althamaniat, Algamoyia, Alseliat).

doi: 10.1371/journal.pone.0080549.g001

\section{Knowledge, Attitude and Practice (KAP) surveys of agricultural pesticide use}

To obtain information on the use of pesticides among farmers, KAP surveys were carried out in urban and peri-urban study sites. A sample of 240 farmers was recruited to answer the questionnaires, 40 from each site. The questionnaire was pre-tested in a village not used as a study site.

\section{DNA extraction, molecular identification and $k d r$ mutations detection}

Sub-samples of dead and live mosquitoes from each insecticidexseason $\times$ study site combination were selected randomly. Genomic DNA was extracted from single mosquitoes following [25], re-suspended in $200 \mu \mathrm{l}$ of $1 \mathrm{X}$ TE-buffer and stored at $-20^{\circ} \mathrm{C}$. Molecular identification of $A n$. arabiensis was carried out using the PCR diagnostic [26]. A total of 250 female mosquitoes from DDT, permethrin and deltamethrin bioassays were genotyped for $k d r 1014$ alleles using allele-specific PCR assay $[27,28]$.

\section{Statistical analysis}

For comparability with other studies, the resistance status of mosquito samples was classified according to the WHO criterion (2013) [24] accordingly, mortality rate $\geq 98 \%=$ susceptible; $90-97 \%$ = suspected/potential resistance; and $<90 \%=$ resistant. Generalized Linear Models (GLM) with a 
Poisson log linear link function was run in SPSS 20 to test the effect of different factors and their interaction on bioassay mortalities. Chi-square contingency tests were used to test the association of $k d r$ with bioassay survivorship for each insecticide, with heterogeneity chi-square tests used to compare association among insecticides. Binomial confidence intervals for bioassays and allele frequencies were computed using Javastat, available at http://statpages.org/confint.html. Moreover, Chi-square test was used to determine the significance of the difference between KAP categorical data (urban and peri-urban sites) using SPSS 20 software. A two sided $p$ value $<0.05$ was considered statistically significant.

\section{Results}

\section{Insecticide susceptibility profiles}

A total of 6000 adult mosquitoes reared from larval collection, from both urban and peri-urban sites across two seasons were identified morphologically as An. gambiae s.I. A subsample of 100 mosquitoes was subjected to PCR; all proved to be An. arabiensis. According to WHO criteria, resistance or potential resistance to all insecticides was detected, with generally highest mortality to deltamethrin and lowest on average to bendiocarb (Figure 2, Table S1, Table S2). GLM analysis indicated that whilst variation among individual sites was not significant, site type was a (marginally) significant factor in determining insecticidal mortality with generally higher mortality in urban than peri-urban sites, but this effect was not consistent across all insecticides (Figure 2, Table 1). In contrast bendiocarb mortality was lower in periurban samples with high variability among individual sample sites.

There was no overall effect of agricultural season on bioassay results with a significant season $x$ insecticide interaction (Table 2 ) driven by seasonal variation in malathion and bendiocarb though the direction of the seasonal effect differed (Figure 2, Table 3). None of the terms in the GLM were significant for DDT or the two pyrethroids.

\section{Kdr frequency and resistance-association}

Of 289 An. arabiensis mosquitoes screened, 250 yielded scorable genotypes for the $k d r 1014$ locus. Kdr 1014S was absent from all screened samples but the $k d r$ L1014F allele was detected in 124 mosquitoes, almost $90 \%$ of which were heterozygotes (Table 4). Owing to relatively low sample sizes, data for seasons were pooled. $K d r$ allele frequencies were very similar in urban (frequency $=0.25 ; 95 \%$ confidence intervals 0.2-0.31) and peri-urban sites (frequency $=0.30 ; 95 \%$ confidence intervals $0.25-0.36$ ). There was a strong and significant association between possession of the $k d r$ allele and bioassay survivorship for DDT, permethrin and deltamethrin in urban and peri-urban sites, with odds ratios between approximately 6 and 15 (Table 4). Whether data were pooled across urban and peri-urban sites to increase power, or treated separately, there was no significant variation in association among the three insecticides.

\section{Knowledge, Attitude and Practice KAP}

The KAP data shows that the most commonly cultivated crops are vegetables in both winter and summer seasons, but that peri-urban farmers grew a greater diversity of other crops, particularly legumes (Table 3 ). The practice of using pesticides was common among all farmers in different sites, with most sourcing the products from private suppliers, although with a greater tendency of peri-urban farmers to obtain formulations from the Ministry of Agriculture (Table 3). Out of 17 agricultural pesticides used, we focused on the classes used by both farmers and public health authorities. Organophosphates and carbamates were by far the most commonly applied pesticides (Figure 3), although there was no difference between urban and peri-urban farmers in the pesticide classes used or the number applied (Figure 3, Table 3). Peri-urban farmers applied pesticides more frequently and were more likely to replace the product with another class if efficacy was perceived to fall (Table 3). Urban farmers were more likely to dispose of pesticides by an approved method, but there was no significant difference in opinion as to whether poor pesticide application practice impacted efficacy (Table 3).

Farmers most commonly complained of heightened mosquito bites at their homes during the summer season but perceived seasonality of biting was greater in urban homes, with more a continuous mosquito density suggested by peri-urban farmers. The majority of farmers used agricultural products for mosquito control in the home. Breeding sites observed in the urban sites were always road puddles, pools and broken pipelines pools while in peri-urban sites were mainly irrigation canals and hoof prints.

\section{Discussion}

The use of agricultural pesticides may have a profound impact on the development of resistance in the field populations of malaria vectors. This study shows that $A n$. arabiensis from urban and peri-urban localities were not fully susceptible to any of the five insecticides tested, though mortality to deltamethrin was generally the highest, and the insecticide for which WHO-defined susceptibility was observed most commonly in individual site $\times$ season combinations.

The ubiquitous detection of suspected resistance to permethrin in all sites is consistent with other studies in Khartoum [3,6] and eastern Africa [20]. However, the prevalence of DDT resistance we detected was higher than detected in previous Sudanese studies [6,29,30]. DDT was banned in Sudan for agricultural use in 1980s, and it is noteworthy that during our KAP agro-sociological surveys we noticed that DDT has been used in agriculture, indicating purchase from illegal markets.

The reduced susceptibility to pyrethroids is of concern for the National Malaria Control Program which depends on efficacious knockdown of mosquitoes by pyrethroids (i.e. ITNs).

The $k d r$ mutation, L1014F, was detected in all urban and peri-urban sites across both summer and winter season. $K d r$ was strongly associated with resistance to pyrethroids and DDT (Table 3 ) suggesting $k d r$ is a primary candidate as a main mechanism underpinning resistance, although metabolic 

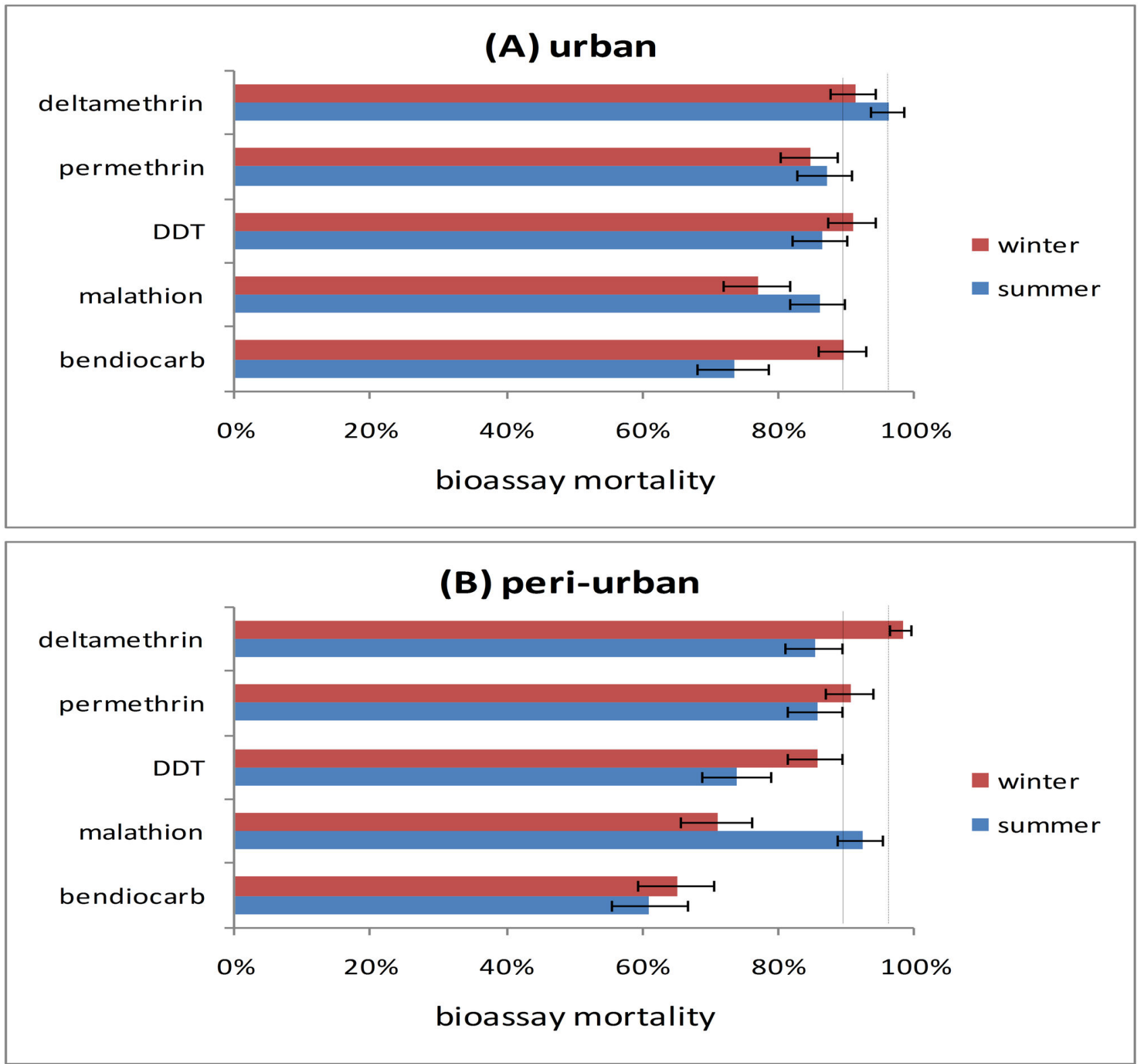

Figure 2. Insecticide resistance bioassay data pooled across sites for mosquitoes collected in each agricultural season in (A) urban and (B) peri-urban sites. Bars show mean mortality with $95 \%$ binomial confidence limits. Solid vertical lines show the WHO mortality threshold for definition of resistant mosquitoes; the dashed lines show the threshold for suspected resistance.

doi: 10.1371/journal.pone.0080549.g002

resistance mechanisms may also be involved in pyrethroid resistance in An. arabiensis [22]. This finding is in concordance with [31] and [32]. In contrast, previous studies have shown either weak [6] or total absent [29,33] of a significant association between $k d r$ mutation and survivorship phenotype indicating that the impact of $k d r$ may be very heterogeneous in $A n$ arabiensis. Of the 17 registered agricultural pesticides applied we focused on those used in agriculture as well as in public health. Organophosphates and carbamates were by far the most commonly used pesticides in agriculture and bendiocarb, the insecticide to which highest levels of resistance were found, particularly in peri-urban sites. Use of the organophosphate malathion by the Khartoum State Malaria Control Program (KSMCP) stopped seven years ago because of development of resistance by mosquitoes vectors (KSMCP, personal communication). Our study confirmed malathion resistance in all urban and peri-urban sites, these results were consistent with other studies in Khartoum [3] . Currently carbamates (e.g. bendiocarb) are not used in public health in Khartoum due to the fact that it has been put as an 
Table 1. Generalized linear model testing the effects of insecticide, season, site type (urban or peri-urban) and site (nested within site-type) on bioassay mortality.

\begin{tabular}{|c|c|c|c|}
\hline Model terms included & $x^{2}$ & d.f. & P-value \\
\hline insecticide & 35.5 & 4 & $3.7 \times 10^{-7}$ \\
\hline site type & 6.5 & 1 & 0.011 \\
\hline site(site type) & 9.2 & 4 & 0.057 \\
\hline insecticide×season & 15.7 & 5 & 0.008 \\
\hline insecticide $\times$ site type & 12.1 & 4 & 0.016 \\
\hline
\end{tabular}

$\mathrm{x}^{2}=$ Chi-square value

d.f $=$ degree of freedom

doi: 10.1371 /journal.pone.0080549.t001

Table 2. Generalized linear model testing the effects of season, site type (urban or peri-urban) and site (nested within sitetype) on bioassay mortality for each insecticide.

\begin{tabular}{|c|c|c|c|c|c|}
\hline Model term & bendiocarb & malathion & DDT & permethrin & deltamethrin \\
\hline site type & 0.0002 & NS & NS & NS & NS \\
\hline Season & 0.0149 & 0.0037 & NS & NS & NS \\
\hline site(site type) & 0.0003 & NS & NS & NS & NS \\
\hline season $\times$ site type & NS & NS & NS & NS & NS \\
\hline season $\times$ site(site type) & 0.0004 & NS & NS & NS & NS \\
\hline
\end{tabular}

NS=not significant

doi: 10.1371/journal.pone.0080549.t002

Table 3. Summary of KAP agro-sociological data: comparison of studied variables between urban and peri-urban sites.

\begin{tabular}{|c|c|c|c|}
\hline Question & $x^{2}$ & P-value & Interpretation \\
\hline Educational level & 15.78 & 0.003 & Urban more educated than peri-urban \\
\hline Crop types cultivated & 35.67 & $9 \times 10^{-8}$ & Peri-urban greater diversity in crops \\
\hline Seasonal difference in crop types & 3.53 & 0.31 & NS \\
\hline Use of pesticides & 2.30 & 0.13 & NS \\
\hline Pesticide class(es) used & 6.57 & 0.08 & NS \\
\hline Number of pesticide classes used & 1.57 & 0.46 & NS \\
\hline Source of pesticides used & 6.51 & 0.011 & Peri-urban use more from Ministry of Agriculture \\
\hline Frequency of pesticide application & 21.39 & $9 \times 10^{-5}$ & Peri-urban apply more frequently \\
\hline Pesticide disposal method & 8.68 & 0.003 & Correct disposal by urban > peri-urban \\
\hline Action if pesticides appear to lose efficiency & 33.09 & $1 \times 10^{-6}$ & Urban tend to increase application, peri-urban to replace product \\
\hline Do you think poor use of pesticide causes loss of effectiveness? & 3.96 & 0.14 & NS \\
\hline Perceived seasonality of mosquito density & 24.80 & 0.0001 & Urban more seasonal, peri-urban more continuous \\
\hline Is mosquito protection used? & 0 & 1 & NS \\
\hline Are mosquitoes targeted using agricultural pesticides? & 3.63 & 0.16 & NS \\
\hline
\end{tabular}

NS=not significant

doi: 10.1371/journal.pone.0080549.t003

alternative insecticide for IRS [34]. Furthermore, some studies has raised up the issues of their toxicity and short residual effect if used in impregnation of bed nets $[34,35,36]$. In our study, it is plausible that the relatively high resistance among the An. arabiensis populations in the six sites, particularly the peri-urban sites (Figure 2), may result from accumulation of carbamates from the heavy agricultural use indicated by our KAP survey. Although there was no significant difference in the type of pesticides used between urban and peri-urban sites, farmers in the latter apply pesticides more frequently. Previous studies in Sudan have detected complete susceptibility of $A n$. arabiensis populations to bendiocarb from Sennar and Gezira $[18,33]$. Bendiocarb is not currently used by NMCP but possible selection for resistance by intensive agricultural use is a concern for future public health plans. Further work is required 
Table 4. Frequencies of L1014F alleles detected in susceptible and resistant mosquitoes of An. arabiensis exposed to DDT, permethrin and deltamethrin.

\begin{tabular}{|c|c|c|c|c|c|c|c|c|c|}
\hline \multirow{2}{*}{ Site Type } & \multirow{2}{*}{ Insecticide } & \multirow{2}{*}{ Phenotype } & \multicolumn{3}{|c|}{ No. per genotype } & \multirow{2}{*}{ Total } & \multirow{2}{*}{$\begin{array}{l}\text { Frequency } \\
\text { L1014F }\end{array}$} & \multirow{2}{*}{ P-value } & \multirow{2}{*}{ OR } \\
\hline & & & LL & LF & FF & & & & \\
\hline \multirow[t]{6}{*}{ urban } & DDT & Dead & 20 & 6 & 0 & 26 & 0.11 & 0.0007 & 7.67 \\
\hline & & Alive & 0 & 12 & 0 & 12 & 0.50 & & \\
\hline & Permethrin & Dead & 24 & 6 & 0 & 30 & 0.10 & $2.539 \times 10^{-7}$ & 12.79 \\
\hline & & Alive & 0 & 19 & 4 & 23 & 0.59 & & \\
\hline & Delatmethrin & Dead & 21 & 6 & 0 & 27 & 0.11 & 0.023 & 8.00 \\
\hline & & Alive & 0 & 4 & 0 & 4 & 0.50 & & \\
\hline \multirow[t]{6}{*}{ Peri-urban } & DDT & Dead & 18 & 11 & 0 & 29 & 0.19 & $1.605 \times 10^{-6}$ & 8.83 \\
\hline & & Alive & 0 & 15 & 8 & 23 & 0.67 & & \\
\hline & Permethrin & Dead & 25 & 5 & 0 & 30 & 0.08 & $2.192 \times 10^{-6}$ & 14.67 \\
\hline & & Alive & 0 & 12 & 2 & 14 & 0.57 & & \\
\hline & Delatmethrin & Dead & 18 & 7 & 0 & 25 & 0.14 & 0.012 & 6.14 \\
\hline & & Alive & 0 & 7 & 0 & 7 & 0.75 & & \\
\hline
\end{tabular}

$\mathrm{L}=$ Leucine (wild- type allele); $\mathrm{F}=$ Phenylalanine ( $k d r$ allele); $\mathrm{P}$-value from $\mathrm{X}^{2}$ test of allelic association; $\mathrm{OR}=$ odds ratio.

The frequencies were calculated for each insecticide and mosquito status (alive/dead) after exposure.

L1014F represent the $k d r$ frequencies

Genotypic odds ratios (ORs) are shown

doi: 10.1371/journal.pone.0080549.t004

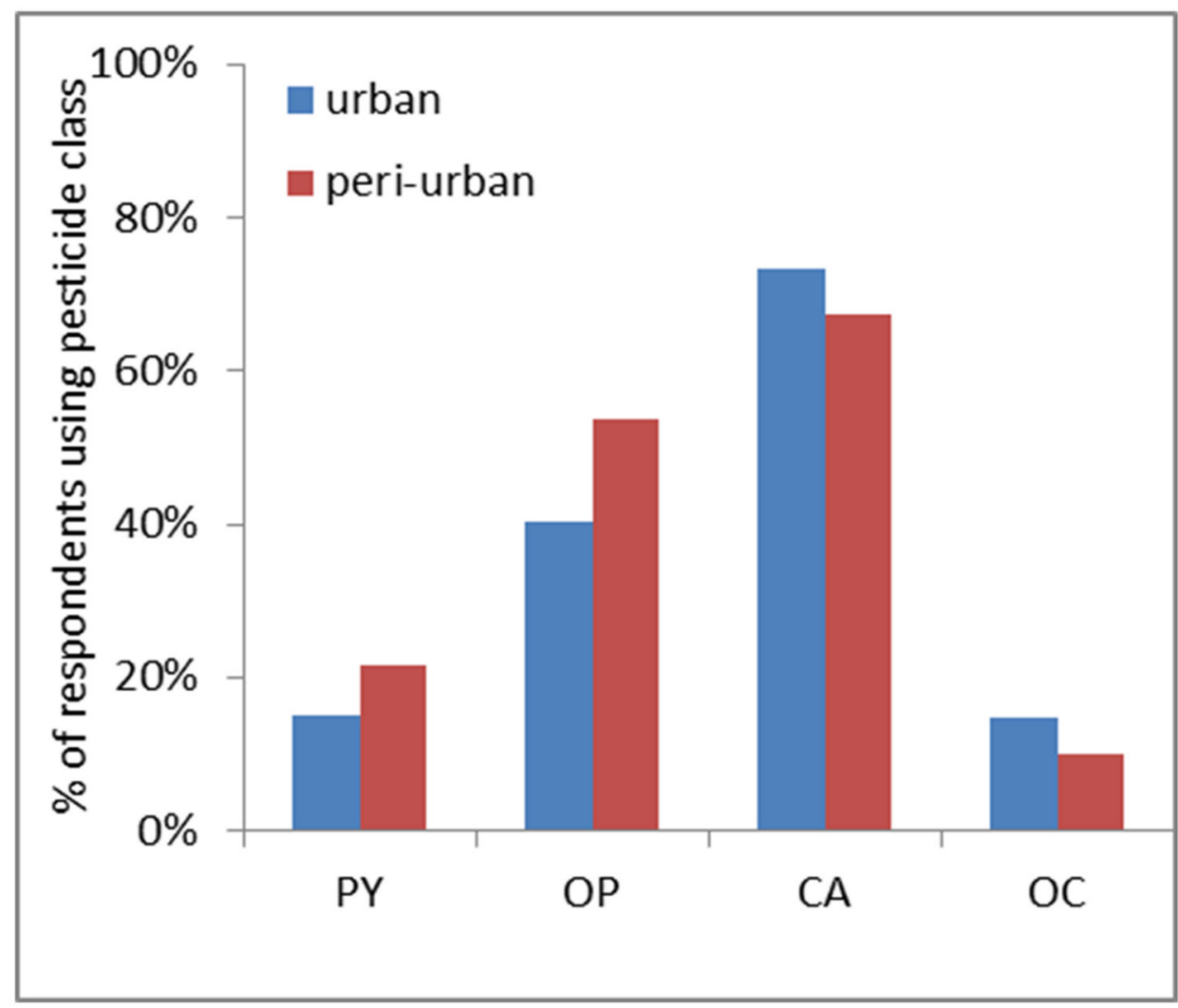

Figure 3. The four pesticides classes used in urban and peri-urban sites during the agro-sociological survey. doi: 10.1371 /journal.pone.0080549.g003 
to establish the mechanistic basis of carbamate resistance in An. arabiensis and its real magnitude on a large scale basis.

In conclusion the present study showed at least some evidence for resistance to five insecticides recommended by WHO for malaria control. Pyrethroid resistance appears to be increasing in Khartoum, which was previously an area of relatively high susceptibility in Sudan [18], perhaps due to an increase in the strongly resistance associated $k d r$ L1014F allele. With scaling-up of ITNs deployment likely, this is a real concern for malaria control programs in the area and continued monitoring of insecticide resistance is warranted. Although establishing a definitive link between agricultural pesticide application and mosquito resistance is difficult, there is much correlational evidence suggesting that such a link frequently exists $[37,38,39,40,41]$. Our data also suggest that agricultural pesticide may be causing or enhancing the development of insecticide resistance. We suggest that these results should be considered when devising rational management strategies for integrated insecticide-based control programs that consider both vectors and crop pests.

\section{Supporting Information}

Table S1. Mortality rates of An. arabiensis bioassyed to DDT $4 \%$, Permethrin $(0.75 \%)$, deltamethrin $0.05 \%$, malathion $5 \%$ and Bendiocarb $(0.1 \%)$ in urban areas in Khartoum, Sudan.

Show the WHO bioassay test results For mortality rate, percentage, and the resistance status after 24 hours exposure to the five insecticides DDT $4 \%$, Permethrin $(0.75 \%)$, deltamethrin $0.05 \%$, malathion $5 \%$ and Bendiocarb $(0.1 \%)$ during winter and summer seasons in urban sites of Khartoum.

* $\mathrm{Cl}=$ confidence interval, Mortality\%: mortality rate 24 hours after exposure to each insecticide. $\neq R$ (Resistant), PR (Potential Resistant) and S (Susceptible).

TAverage of five replicates each consists of 20 female mosquitoes.

Number of tested mosquitoes per insecticide per site per season $=100$.

(DOC)

Table S2. Mortality rates of An. arabiensis bioassyed to DDT 4\%, Permethrin (0.75\%), deltamethrin $0.05 \%$,

\section{References}

1. Malik EM, Ahmed ES, Elkhalifa SM, Hussein MA, Sulieman AM (2003) Stratification of Khartoum urban area by the risk of malaria transmission. East Mediterr Health J 9: 559-569. PubMed: 15748053.

2. Nourein AB, Abass MA, Nugud AH, El Hassan I, Snow RW et al. (2011) Identifying residual foci of Plasmodium falciparum infections for malaria elimination: the urban context of Khartoum, Sudan. PLOS ONE 6: e16948. doi:10.1371/journal.pone.0016948. PubMed: 21373202.

3. Seidahmed OM, Abdelmajed MA, Mustafa MS, Mnzava AP (2012) Insecticide susceptibility status of the malaria vector Anopheles arabiensis in Khartoum city, Sudan: differences between urban and periurban areas. East Mediterr Health J 18: 769-776. PubMed: 22891527.

4. WHO (2010) World Malaria Report. Executive summary and key points. Available: http://www.who.int/malaria/world_malaria_report_2010/ malaria2010-summary-Available online at: keypoints-en.pdf.

5. WHO (2012) World malaria report (2012). World Health Organization.
Malathion $(5 \%)$ and Bendiocarb $(0.1 \%)$ in peri-urban areas in Khartoum, Northern Sudan.

Show the WHO bioassay test results For mortality rate, percentage, and the resistance status after 24 hours exposure to the five insecticides DDT $4 \%$, Permethrin $(0.75 \%)$, deltamethrin $0.05 \%$, malathion $5 \%$ and Bendiocarb $(0.1 \%)$ during winter and summer seasons in peri-urban sites of Khartoum.

* $\mathrm{Cl}=$ confidence interval, Mortality\%: mortality rate 24hours after exposure to each insecticide. $\neq R$ (Resistant), PR (Potential Resistant) and S (Susceptible).

IAverage of five replicates each consists of 20 female mosquitoes.

Number of tested mosquitoes per insecticide per site per season $=100$.

(DOC)

\section{Acknowledgements}

We are grateful for Mr Mustafa Mohieldin, Mrs Samar Gamal, for their assistance in KAP field surveys and Miss Omnia Fathelrhman Abdelwhab for performing DNA extraction. We thank Mr Salah-Eldin El-zaki from Tropical Medicine Research Institute for continuous valuable molecular support guidance and Mr. Telal Ageep for providing study sites coordinates and map. We thank Ahmed Ibrahim for the field work of mosquito collection. We also thank Mohamed S. Muneer a fourth year medical student, University of Khartoum for providing excellent assistance and discussion on the statistical work. We also thank Prof Mark Benedict for providing suggestions helpful for revising the manuscript.

\section{Author Contributions}

Conceived and designed the experiments: SAA OMES FTAA. Performed the experiments: SAA AHE MAB HFAE. Analyzed the data: EAF DW MAB MMA. Contributed reagents/materials/ analysis tools: SAA DW. Wrote the manuscript: SAA AHE DW MMA. Entomological field surveys: HFAE. Provide extraction protocol and Manuscript writing supervision: MMA. Manuscript essential revision for several time: OMES.

6. Himeidan YE, Muzamil HM, Jones CM, Ranson H (2011) Extensive permethrin and DDT resistance in Anopheles arabiensis from eastern and central Sudan. Parasit Vectors 4: 154. doi: 10.1186/1756-3305-4-154. PubMed: 21812972.

7. Elkhalifa SM, Mustafan IO, Wais M, Malik EM (2008) Malaria control in an urban area: a success story from Khartoum, 1995-2004. East Mediterr Health J 14: 206-215. PubMed: 18557470.

8. Petrarca V, Nugud AD, Ahmed MA, Haridi AM, Di Deco MA et al. (2000) Cytogenetics of the Anopheles gambiae complex in Sudan, with special reference to An. arabiensis: relationships with East and West African populations. Med Vet Entomol 14: 149-164. doi:10.1046/j. 1365-2915.2000.00231.x. PubMed: 10872859.

9. Onwujekwe O, Uzochukwu B, Ezumah N, Shu E (2005) Increasing coverage of insecticide-treated nets in rural Nigeria: implications of consumer knowledge, preferences and expenditures for malaria 
prevention. Malar J 4: 29. doi:10.1186/1475-2875-4-29. PubMed: 16026623.

10. Santolamazza F, Calzetta M, Etang J, Barrese E, Dia I et al. (2008) Distribution of knock-down resistance mutations in Anopheles gambiae molecular forms in west and west-central. Africa - Malar J 7: 1475-2875.

11. Ranson H, N'Guessan R, Lines J, Moiroux N, Nkuni Z et al. (2011) Pyrethroid resistance in African anopheline mosquitoes: what are the implications for malaria control? Trends Parasitol 27: 91-98. doi: 10.1016/j.pt.2010.08.004. PubMed: 20843745.

12. Chandre F, Darrier F, Manga L, Akogbeto M, Faye O et al. (1999) Status of pyrethroid resistance in Anopheles gambiae sensu lato. Bull World Health Organ 77: 230-234. PubMed: 10212513.

13. Balkew M, Ibrahim M, Koekemoer LL, Brooke BD, Engers $\mathrm{H}$ et al. (2010) Insecticide resistance in Anopheles arabiensis (Diptera: Culicidae) from villages in central, northern and south west Ethiopia and detection of $\mathrm{kdr}$ mutation. Parasit Vectors 3: 40. doi: 10.1186/1756-3305-3-40. PubMed: 20416109.

14. Diabate A, Brengues C, Baldet T, Dabiré KR, Hougard JM et al. (2004) The spread of the Leu-Phe kdr mutation through Anopheles gambiae complex in Burkina Faso: genetic introgression and de novo phenomena. Trop Med Int Health 9: 1267-1273. doi:10.1111/j. 1365-3156.2004.01336.x. PubMed: 15598258.

15. Kulkarni MA, Rowland M, Alifrangis M, Mosha FW, Matowo $\mathrm{J}$ et al. (2006) Occurrence of the leucine-to-phenylalanine knockdown resistance $(\mathrm{kdr})$ mutation in Anopheles arabiensis populations in Tanzania, detected by a simplified high-throughput SSOP-ELISA method. Malar J 5: 56. doi:10.1186/1475-2875-5-56. PubMed: 16820067.

16. Yewhalaw D, Bortel WV, Denis L, Coosemans M, Duchateau L et al. (2010) First evidence of high knockdown resistance frequency in Anopheles arabiensis (Diptera: Culicidae) from Ethiopia. Am J Trop Med Hyg 83: 122-125. doi:10.4269/ajtmh.2010.09-0738. PubMed: 20595490.

17. USAID (2010) The President's Malaria Initiative: fourth annual report. In. Washigton. U.S. Agency for International Development

18. Ranson H, Abdallah H, Badolo A, Guelbeogo WM, Kerah-Hinzoumbé C et al. (2009) Insecticide resistance in Anopheles gambiae: data from the first year of a multi-country study highlight the extent of the problem. Malar J 8: 299. doi:10.1186/1475-2875-8-299. PubMed: 20015411.

19. Hemingway J (1983) Biochemical studies on malathion resistance in Anopheles arabiensis from Sudan. Trans R Soc Trop Med Hyg 77: 477-480. doi:10.1016/0035-9203(83)90118-9. PubMed: 6636275

20. Yewhalaw D, Wassie F, Steurbaut W, Spanoghe P, Van Bortel W et al. (2011) Multiple insecticide resistance: an impediment to insecticidebased malaria vector control program. PLOS ONE 6: e16066. doi: 10.1371/journal.pone.0016066. PubMed: 21264325

21. Reimer L, Fondjo E, Patchoké S, Diallo B, Lee Y et al. (2008) Relationship between kdr mutation and resistance to pyrethroid and DDT insecticides in natural populations of Anopheles gambiae. J Med Entomol 45: 260-266. Available online at: 10.1603/0022-2585(2008)45[260:RBKMAR]2.0.CO;2;2. PubMed: 18402142

22. Matowo J, Kulkarni MA, Mosha FW, Oxborough RM, Kitau JA et al. (2010) Biochemical basis of permethrin resistance in Anopheles arabiensis from Lower Moshi, north-eastern Tanzania. Malar J 9: 1475-2875. PubMed: 20609220.

23. Gillies MT, Coetzee M (1987) A supplement to the Anophelinae of Africa Southof the Sahara (Afrotropical Region). Publications of the South African Institutefor Medical Researchno. p. 55.

24. WHO (2013) Test procedures for insecticide resistance monitoring in malaria vector mosquitoes. Available: http://apps.who.int/iris/bitstream/ 10665/80139/1/9789241505154_eng.pdf. p. 18. WHO Library Cataloguing-in-Publication Data.

25. Collins FH, Mendez MA, Rasmussen MO, Mehaffey PC, Besansky NJ et al. (1987) A ribosomal RNA gene probe differentiates member species of the Anopheles gambiae complex. Am J Trop Med Hyg 37: 37-41. PubMed: 2886070.
26. Scott JA, Brogdon WG, Collins FH (1993) Identification of single specimens of the Anopheles gambiae complex by the polymerase chain reaction. Am J Trop Med Hyg 49: 520-529. PubMed: 8214283.

27. Martinez-Torres D, Chandre F, Williamson MS, Darriet F, Bergé JB et al. (1998) Molecular characterization of pyrethroid knockdown resistance $(\mathrm{kdr})$ in the major malaria vector Anopheles gambiae s.s. Insect Mol Biol 7: 179-184. doi:10.1046/j.1365-2583.1998.72062.x. PubMed: 9535162.

28. Ranson H, Jensen B, Vulule JM, Wang X, Hemingway J et al. (2000) Identification of a point mutation in the voltage-gated sodium channel gene of Kenyan Anopheles gambiae associated with resistance to DDT and pyrethroids. Insect Mol Biol 9: 491-497. doi:10.1046/j. 1365-2583.2000.00209.x. PubMed: 11029667.

29. Abdalla H, Matambo TS, Koekemoer LL, Mnzava AP, Hunt RH et al. (2008) Insecticide susceptibility and vector status of natural populations of Anopheles arabiensis from Sudan. Trans R Soc Trop Med Hyg 102: 263-271. doi:10.1016/j.trstmh.2007.10.008. PubMed: 18054056.

30. Himeidan YE, Chen H, Chandre F, Donnelly MJ, Yan G (2007) Short report: permethrin and DDT resistance in the malaria vector Anopheles arabiensis from eastern Sudan. Am J Trop Med Hyg 77: 1066-1068. PubMed: 18165523

31. Diabaté A, Baldet T, Chandre F, Dabire KR, Simard F et al. (2004) First report of a kdr mutation in Anopheles arabiensis from Burkina Faso, West Africa. J Am Mosq Control Assoc 20: 195-196. PubMed: 15264630.

32. Donnelly MJ, Corbel V, Weetman D, Wilding CS, Williamson MS et al. (2009) Does kdr genotype predict insecticide-resistance phenotype in mosquitoes? Trends Parasitol 25: 213-219. doi:10.1016/j.pt. 2009.02.007. PubMed: 19369117.

33. Matambo TS, Abdalla H, Brooke BD, Koekemoer LL, Mnzava A et al. (2007) Insecticide resistance in the malarial mosquito Anopheles arabiensis and association with the kdr mutation. Med Vet Entomol 21: 97-102. doi:10.1111/j.1365-2915.2007.00671.x. PubMed: 17373952.

34. Akogbéto MC, Padonou GG, Gbénou D, Irish S, Yadouleton A (2010) Bendiocarb, a potential alternative against pyrethroid resistant Anopheles gambiae in Benin, West Africa. Malar J 9: 204. doi: 10.1186/1475-2875-9-204. PubMed: 20630056.

35. Fanello C, Carneiro I, Ilboudo-Sanogo E, Cuzin-Ouattara N, Badolo A et al. (2003) Comparative evaluation of carbosulfan- and permethrinimpregnated curtains for preventing house-entry by the malaria vector Anopheles gambiae in Burkina Faso. Med Vet Entomol 17: 333-338. doi:10.1046/j.1365-2915.2003.00450.x. PubMed: 12941019.

36. Guillet $P$, N'Guessan R, Darriet F, Traore-Lamizana M, Chandre F et al. (2001) Combined pyrethroid and carbamate 'two-in-one' treated mosquito nets: field efficacy against pyrethroid-resistant Anopheles gambiae and Culex quinquefasciatus. Med Vet Entomol 15: 105-112. doi:10.1046/j.1365-2915.2001.00288.x. PubMed: 11297094.

37. Antonio-Nkondjio C, Fossog BT, Ndo C, Djantio BM, Togouet SZ et al. (2011) Anopheles gambiae distribution and insecticide resistance in the cities of Douala and Yaounde (Cameroon): influence of urban agriculture and pollution. Malar J 10: 154. doi: 10.1186/1475-2875-10-154. PubMed: 21651761.

38. Diabate A, Baldet T, Chandre F, Akoobeto M, Guiguemde TR et al. (2002) The role of agricultural use of insecticides in resistance to pyrethroids in Anopheles gambiae s.I. in Burkina Faso. Am J Trop Med Hyg 67: 617-622. PubMed: 12518852.

39. Müller $P$, Chouaïbou M, Pignatelli $P$, Etang J, Walker ED et al. (2008) Pyrethroid tolerance is associated with elevated expression of antioxidants and agricultural practice in Anopheles arabiensis sampled from an area of cotton fields in Northern Cameroon. Mol Ecol 17: 1145-1155. PubMed: 18179425

40. Yadouleton AW, Asidi A, Djouaka RF, Braïma J, Agossou CD et al. (2009) Development of vegetable farming: a cause of the emergence of insecticide resistance in populations of Anopheles gambiae in urban areas of Benin. Malar J 8: 103. doi:10.1186/1475-2875-8-103. PubMed: 19442297.

41. Yadouleton AW, Padonou G, Asidi A, Moiroux N, Bio-Banganna S et al. (2010) Insecticide resistance status in Anopheles gambiae in southern Benin. Malar J 9: 83. doi:10.1186/1475-2875-9-83. PubMed: 20334637. 